\title{
БИС считывания с инкрементальным $\Delta \Sigma$-АЦП в столбце для цифровой МФПУ сканирующего типа с режимом ВЗН
}

\author{
Ю.А. Якимов, И.С. Мощев, М.Л. Храпунов, В.А. Стрельцов, А.Н. Кузнецов, П.А. Кузнецов \\ ${ }^{1}$ ГНЦ АО «НПО Орион», Москва, ул. Косинская, д.9. \\ тел: +7 (962) 965-0973, эл. почта: iu-iakimov@yandex.ru
}

DOI 10.34077/RCSP2021-146

Задача регистрации малоразмерных объектов часто решается с помощью применения многорядных ФПУ с режимом временной задержки и накопления (ВЗН), к которым предъявляются высокие требования по характеристикам и функциональным возможностям. В первую очередь эти требования распространяются на предварительную обработку и оцифровку сигнала, выполняемую в БИС считывания.

Представлен результат разработки большой интегральной схемы (БИС) считывания для усиления и обработки сигнала фотоприёмного устройства (ФПУ) коротковолнового ИК-диапазона сканирующего типа формата $1024 \times 10$ с цифровым выходом. В состав фоточувствительного модуля входит матрица фоточувствительных элементов из $\mathrm{CdHgTe}$, состыкованная с кремниевой БИС, имеющей следующую структуру: четыре субматрицы 256x10, сдвинутые на 15 мкм поперек направления сканирования, входные ячейки размером 60х45 мкм, далее сигнал коммутируется в блок В3Н суммирования, после которого следует блок 1024 каналов $\Delta \Sigma$-АЦП с разрешением 14 бит. Реализован новый способ расширения динамического диапазона с использованием схемы динамического антиблюминга, а также способ снижения шума с помощью фильтра на переключаемых конденсаторах.

В каждом канале БИС располагается 10 входных ячеек вдоль направления сканирования. Входной каскад, в котором происходит накопление фотозаряда, выполнен на схеме емкостного трансимпедансного усилителя (CTIA) с накопительной емкостью 6 фФ. Высокая чувствительность необходима для детектирования малого фототока (до 100 пА) за небольшое время интегрирования примерно 200-300 мкс. У данной схемы имеется ряд особенностей и новых решений. Применяется дополнительный разделительный конденсатор на входе, позволяющий стабилизировать смещение фотодиода. В связи с использованием малой емкости интегрирования в обратной связи, добавлен каскодный транзистор, которой отсекает паразитную емкость. Для устранения влияния разброса порогового напряжения транзисторов и низкочастотных шумов применяется двойная коррелированная выборка (ДКВ).

Также в данной схеме применяется новый способ реализации динамического HDR с кусочнолинейной характеристикой с помощью автоподстройки времени интегрирования индивидуально в каждой ячейке [1]. Вторым нововведением в ячейке является применение фильтра нижних частот на переключаемых конденсаторах (ФНЧ) в схеме выходного каскада, что позволяет снизить шум за счет усреднения [2]. Предусмотрен также режим, в котором фильтр конфигурируется в схему подстройки коэффициента усиления от 1 до 2,5 раз. В выходном каскаде реализовано переключение режима по постоянному и переменному сигналу с нижней граничной частотой 35 Гц, а также подстройка постоянной составляющей.

В микросхеме реализован режим ВЗН в аналоговой форме на пожарной цепочке по 10 элементам. В таком режиме сигналы с ячеек в канале последовательно суммируются, за счет чего повышается соотношение сигнал/шум. Это уменьшает также разброс параметров и позволяет исключить дефектные элементы. В блоке ВЗН имеется дополнительный ФНЧ, а также регулирование коэффициента усиления.

Оцифровка сигнала в каждом канале осуществляется с помощью малопотребляющего АЦП в столбце разрядностью 14 бит. Архитектура двухкаскадного инкрементального $\Delta \Sigma$-АЦП позволяет получить высокую скорость работы при малой мощности и снизить широкополосный шум входного тракта за счет оверсэмплинга.

\section{Лuтература}

[1] Кузнецов П. А., Мощев И. С. Расширение динамического диапазона коротковолновых ИК матричных фотоприемных устройств // Прикладная физика. 2017. № 5. С. 52.

[2] Стрельцов В. А., Козлов К. В., Смирнова О. Д. Оптимизация частотной характеристики многорядных фотоприемных устройств для регистрации малоразмерных объектов // Успехи прикладной физики. 2018. Т. 6. № 6. С. 526. 